\title{
Determinants of practice of preconception care among women of reproductive age group in southern Ethiopia, 2020: content analysis
}

\author{
Aklilu Habte ${ }^{1^{*}} \mathbb{D}$, Samuel Dessu ${ }^{2}$ and Dereje Haile ${ }^{3}$
}

\begin{abstract}
Background: Preconception care (PCC) is a series of biomedical, mental, and psycho-social health services provided to women and a couple before pregnancy and throughout subsequent pregnancies for desired outcomes. Millions of women and new-borns have died in low-income countries due to impediments that arise before and exaggerate during pregnancies that are not deal with as part of pre-conception care. To the best of our knowledge, however, there is a lack of information about preconception care practice and its determinants in southern Ethiopia, including the study area. This study was therefore planned to assess the practice of preconception care and its determinants among mothers who recently gave birth in Wolkite town, southern Ethiopia, in 2020.
\end{abstract}

Methods: A community-based cross-sectional study was conducted from February 1 to 30, 2020. A total of 600 mothers who have given birth in the last 12 months have been randomly selected. A two-stage sampling technique was employed. For data collection, a pre-tested, semi-structured questionnaire was used. The data was encoded and entered into Epi-Data version 3.1 and exported for analysis to SPSS version 23. Household wealth status was determined through the application of principal component analysis(PCA). The practice PCC was considered as a count variable and measured as a minimum score of 0 and a maximum of 10 . A bivariable statistical analysis was performed through analysis of variance (ANOVA) and independent t-tests and variables with a $p$-value of $<0.05$ were eligible for the generalized linear regression model. To see the weight of each explanatory variable on PCC utilization, generalized linear regression with a Poisson link was done.

Results: Of the sampled 600 participants, 591 took part in the study, which yielded a response rate of $98.8 \%$.The mean $( \pm S D)$ score of the practice of PCC was 3.94 ( \pm 1.98 ) with minimum and maximum scores of 0 and 10 respectively. Only $6.4 \%(95 \% \mathrm{Cl}: 4.6,8.6)$ of mothers received all selected items of PCC services. Thecommonest item received by $67.2 \%$ of mothers was Folic acid supplementation, while $16.1 \%$ of mothers received the least item of optimizing psychological health. Education status of mother[AOR $0.74,95 \% \mathrm{Cl} 0.63,0.97]$, time spent to access nearby health facilities [AOR $0.69,95 \% \mathrm{Cl} 0.58,0.83$ ], availability of PCC unit [AOR 1.46; 95\%Cl 1.17, 1.67], mother's knowledge on PCC [AOR $1.34,95 \% \mathrm{Cl} 1.13,1.65]$, being a model household [AOR 1.31,95\% Cl 1.18, 1.52] and women's autonomy in decision making [AOR $0.75,95 \% \mathrm{Cl} 0.64,0.96]$ were identified as significant predictors of practice of PCC.

Conclusion: The uptake of WHO-recommended PCC service elements in the current study area was found to be unsatisfactory. Stakeholders must therefore increase their efforts to align PCC units with existing MNCH service

*Correspondence: akliluhabte57@gmail.com

${ }^{1}$ Department of Public Health, College of Medicine and Health Sciences,

Wachemo University, Hosanna, Ethiopia

Full list of author information is available at the end of the article

(c) The Author(s) 2021. Open Access This article is licensed under a Creative Commons Attribution 4.0 International License, which permits use, sharing, adaptation, distribution and reproduction in any medium or format, as long as you give appropriate credit to the original author(s) and the source, provide a link to the Creative Commons licence, and indicate if changes were made. The images or other third party material in this article are included in the article's Creative Commons licence, unless indicated otherwise in a credit line to the material. If material is not included in the article's Creative Commons licence and your intended use is not permitted by statutory regulation or exceeds the permitted use, you will need to obtain permission directly from the copyright holder. To view a copy of this licence, visit http://creativecommons.org/licenses/by/4.0/. The Creative Commons Public Domain Dedication waiver (http://creativeco mmons.org/publicdomain/zero/1.0/) applies to the data made available in this article, unless otherwise stated in a credit line to the data. 
delivery points, improve women's decision-making autonomy, and focus on behavioral change communication to strengthen PCC practice.

\section{Plain language summary}

Preconception care (PCC) is a series of biomedical, mental, and psycho-social health services provided to women and a couple before pregnancy and throughout subsequent pregnancies for better endings. The main goal of the PCC is to improve maternal and child health outcomes, by-promoting wellness and providing preventive care. It can also be seen as an earlier chance for teenage girls, mothers, and children to live a better and longer-term healthy life. Pieces of PCC service packages suggested by the World Health Organization(WHO) are, micronutrient supplementation (Folate supplementation), infectious disease (STI/HIV) screening and testing, chronic disease screening and management, healthy diet therapy, vaccination, prevention of substance use (cessation of cigarette smoking and too much alcohol consumption), optimizing psychological health, counseling on the importance of exercise and reproductive health planning and implementation. Millions of women and new-borns have died in low-income countries due to impediments that arise before and exaggerate during pregnancies that are not deal with as part of pre-conception care. To the best of our knowledge, however, there is a lack of information about preconception care practice and its determinants in southern Ethiopia, including the study area. This study was therefore planned to evaluate the practice of preconception care and its determinants among mothers who recently gave birth in Wolkite town, southern Ethiopia, in 2020.

Mothers who have given birth in the last 12 months have been randomly selected Household wealth status was determined through the application of principal component analysis(PCA). To see the weight of each explanatory variable on PCC, generalized linear regression with a Poisson type was done. Accordingly, the Education status of the mother, time spent to access nearby health facilities, availability of PCC unit, mother's knowledge on PCC, being a model household, and women's autonomy in decision making were identified as significant predictors of practice of PCC. Stakeholders must therefore increase their efforts to align PCC units with existing MNCH service delivery points, improve women's decision-making autonomy, and focus on behavioral change communication to strengthen PCC practice.

Keywords: Preconception care, Contents of care, Determinants, Ethiopia

\section{Background}

Preconception care (PCC) is a series of biomedical, mental, and psycho-social health services offered to women and a couple before pregnancy and throughout subsequent pregnancies $[1,2]$. It is the earliest connection between maternal and infant health and a window of opportunity to reinforce the health of women before, during, and after pregnancy through early detection and risk management $[3,4]$. It is a part of the Healthy People initiative that focuses profoundly on tackling unwanted pregnancies [5]. The main goal of PCC is to improve maternal and child health outcomes by promoting wellness and providing preventive care. It can also be seen as an earlier opportunity for adolescent girls, mothers, and children to live a better and longer-term healthy life $[6$, 7].

Preconception care offers a variety of services in the sense of prevention aimed at mothers and newborns $[8,9]$. Several pieces of PCC service packages were suggested by the World Health Organization(WHO), including micronutrient supplementation (ferrous supplementation), infectious disease (STI/HIV) screening and testing, chronic disease screening and management, healthy diet therapy, vaccination, prevention of substance use (cessation of cigarette smoking and too much alcohol consumption), optimizing psychological health, counseling on the importance of exercise and reproductive health planning and implementation $[1,10,11]$.

Pregnancy and childbirth complications resulted in the deaths of 830 and 303,000 women daily and annually, respectively, as well as a great deal of suffering and longterm disabilities [12]. More than 3.1 million newborns died in their first month of life around the world, with 14.9 million born prematurely and 2.7 million stillborn [13]. According to the Ethiopian Demographic Health Survey (EDHS) 2016 report, the pregnancy-related mortality ratio was 412 per 100,000 live births and the lifetime risk of pregnancy-related death is 21 in 1000 women [14]. Most of these complications happen before and get worse during pregnancy, especially if they are not treated as part of PCC [15].

The Sustainable Development Goal (SDG) set a goal of minimizing the ratio of maternal mortality below 70 per 100,000 live births and the rate of newborn mortality (NMR) to 12 per 1000 live births and s globally in 2030 [16]. PCC helps in achieving this goal by reducing adverse 
birth outcomes like preterm birth, low birth weight, and congenital defects by expanding access to high-quality PCC service packages [17-19].

PCC is among the key programs in the continuum of care $(\mathrm{COC})$ for maternal neonatal and child health $(\mathrm{MNCH})$ care $[20,21]$. According to the recommendation of the Center for Disease Control (CDC), every childbearing woman should obtain a risk assessment during her primary health care visit to realize good pregnancy and maternity outcomes [22]. In contrast, millions of women all around the globe do not have access to preconception service packages, especially in low-income countries [23]. Recent reports have shown that approximately $40 \%$ of global women have undergone unplanned pregnancies, suggesting that 4 out of 10 women do not have vital health intervention packages before conception $[16,24]$.

Studies conducted in Utah, Brazil, China, Sri Lanka, and Saudi Arabia, have shown a low level of PCC service uptake of $15.9-32.1 \%$ for women of reproductive age [25-29]. Studies conducted in Ethiopia have shown that the practice of PCC necessitates further enhancement with a magnitude of 9.6-38.2\% [30-34]. Factors such as maternal age, level of education, occupational status, prior history of adverse birth outcomes, pregnancy planning status, PCC awareness, and PCC unit availability have been identified as possible deteminats [30-33].

While the PCC is one of Healthy People 2020's major strategic objectives, it has not been extensively understood and practiced, especially in low-income countries, including Ethiopia $[6,35,36]$. In contrast with other Continuum of Care (COC) maternal and child health services, the PCC can be viewed as the missing continuum elements [37]. Besides, the CDC renowned that PCC packages are not acknowledged by most people and would need more intervention $[7,38]$.

Although the Ethiopian government has given due importance over the last decades to maternal and child health services in terms of prenatal care, skilled delivery service, and postpartum care, adverse pregnancy outcomes and congenital defects are-at a frightening rate [39]. These adverse pregnancy outcomes will raise the risk of noncommunicable diseases like cardiovascular disease and other chronic diseases in both mothers and children, thereby promoting transgenerational disease [38]. In recent decades, good accomplishments have been noted in the overall prenatal care service, but the median month for the first ANC visit is 4.7 months [14]. This late ANC initiation can be reduced by providing adequate pregnancy preparation through the integration of PCC with $\mathrm{MNCH}$ services $[1,8,38]$. PCC service packages are currently available on a range of service delivery channels, but there are still many shortcomings in providing the service on a daily and regular basis [30, 32, 33, 39]. Little is known, including the current study area, about the practice of PCC and its determinants among childbearing women in Wolkite town, southern Ethiopia.

Assessing the level of PCC experience and its determinants allows policymakers to foresee the PCC needs of women and couples before pregnancy, ensuring that motherhood and childhood are off to the safest start possible. This research was therefore intended to examine the practice of PCC and to recognize determinants. Also, the research will contribute to the creation and implementation of successful strategies to increase service adoption and, ultimately, to resolve the increasing burden of pregnancy and adverse outcomes.

\section{Materials and methods \\ Study design and settings}

The Community-based cross-sectional study was conducted from 1 to 30 February 2020 in Wolkite town, southern Ethiopia. The town is located $151 \mathrm{~km}$ southeast of the capital city, Addis Ababa. Administratively, the town is divided into 13 kebeles (Kebele is the smallest administrative unit in Ethiopia). The projected total population of the town for the 2020 fiscal year was 102,948 $($ Male $=55,858$, Female $=52,090)$, based on the 2007 CSA forecast. The total number of women in the reproductive age group (15-49 years) was 23,246, representing $22.6 \%$ of the population as a whole. In the town that was providing maternal and child health services, there are a total of 19 health facilities and further quantified as one teaching and referral hospital, two health centers, 10 health posts, and six medium clinics.

\section{The population of the study}

The source populations for this study were all mothers in the town who had given birth in the preceding 12 months. The study population is made up of women in seven randomly selected kebeles in the town who come across eligibility criteria. Women who had lived in the study area for less than 6 months and were critically ill at the time of data collection were excluded from the study.

\section{Sample size determination}

The sample size for the study was determined by applying the single population proportion formula. The parameters such as the reported prevalence of PCC practice, which is $38.2 \%$ from a study conducted in western Ethiopia [34], a 95\% confidence level, 5\% margins of error, 1.5\% design effect, and $10 \%$ non-response rate was used. Consequently, the final sample size for the study was 600 . 


\section{Sampling techniques}

To get study participants, a two-stage sampling technique was used. There are 13 Kebeles in the town, and seven of them were chosen randomly by lottery method. The total number of mothers who had given birth in the previous 12 months in each kebele was taken from the delivery registration books located in health posts. The sample size for each kebele was distributed by proportional allocation and each study participant was accessed by using the lottery method. When more than one eligible woman was identified in the chosen household, a lottery method was applied.

\section{Data collection tools, techniques, and personnel}

Six diploma nurses with previous data collection experience conducted face-to-face interviews under the supervision of three BSc Midwives, using a pre-tested, standardized questionnaire. Both data collectors and supervisors were given intense training that lasted one day. An intensive training that lasts one day was provided to both data collectors and supervisors. The data collection tool was developed after reviewing relevant literature in the field of interest $[1,8,31,33]$. The questionnaire contains socio-demographic variables, obstetric variables, health system-related features, and respondents' knowledge of PCC. The wealth status of households was evaluated using a standardized questionnaire adapted from EDHS 2016 [14]. The pre-test was conducted prior to the actual data collection. Women were contacted with the guidance of local community health workers (CHWs) in each Kebele. The list of women selected for the interview in each kebele was provided in advance to the data collectors. The data were collected on a house-to-house basis.

\section{Data quality management}

The questionnaire used to collect data was initially prepared in English, then translated into the local language by an expert in that language, and then re-translated into English to ensure consistency with the original meanings. One-day intensive training was provided to both data collectors and supervisors on the purpose of the study, the content of the questionnaire, and the method of data collection was. A pretest among $5 \%$ of the sample size (30 respondents) was conducted in Wolliso town, and possible adjustments were made for the better completion of the questionnaire. A day-to-day follow-up during the data collection period was carried out by the principal investigator and supervisors. Before entering the data, the supervisors checked it for completeness and consistency. Incomplete data were omitted from the analysis. To reduce social desirability bias, study participants were interviewed privately.

\section{Data analysis}

The data was coded and entered into Epi Data Version 3.1 and exported to SPSS version 23 for analysis. Descriptive statistics such as frequencies, mean, and standard deviation were computed to describe the characteristics of the respondents. The wealth status of households was determined by applying principal component analysis (PCA). Initially, 27 items were used and grouped into six components, namely: household properties, livestock ownership, crop production in quintal, the average estimated monthly income, hectares of agricultural land, and housing conditions. Fulfillment of PCA assumptions such as; overall sampling adequacy ( $\mathrm{KMO} \geq 0.6)$, sampling adequacy of individual variables (anti-image correlations $>0.4$ ), Bartlett Sphericity Test (p-value $<0.05)$ were checked. In each step, these variables with communities less than 0.5 and complex structures (i.e. having correlations greater than 0.4 in more than one component) were removed before the criteria were met iteratively. Finally, three components were extracted from the PCA that clarified a total variance of $66.94 \%$ and used to rate the study participants' household wealth status in quintiles [14].

A bivariable analysis using analysis of variance (ANOVA) and independent t-tests had been used to test statistical significance, and variables with a $\mathrm{p}$-value of 0.05 were eligible for a generalized linear regression model. Multivariable statistical analysis using the Generalized Linear Model (GLM) approach was used to classify the determinants of PCC practice. A Poisson regression model with a log link was used since our response variable was measured in terms of count variables [40]. The property of equidispersion, which states that the variance of a distribution of count-dependent variables is equal to its mean, is one of the basic assumptions of Poisson regression [40,41], and the current study almost meets this criterion with mean and variance of 3.940 and 3.938, respectively. Finally, the odds ratios and 95\% confidence intervals for each independent variable were calculated. The strength and direction of the association were determined using crude and adjusted odds ratios. Charts, graphs, and figures were used to display the information.

\section{Variables of the study \\ Dependent variable}

Preconception care: the complete range of interventions to promote the well-being of the expectant mother and the baby [1]. The ten selected items of PCC services considered in this study were: Folic acid supplementation, vaccination, screening and management of infectious diseases (STI/HIV), screening and management of chronic diseases, balanced diet therapy, cessation of cigarette smoking, avoidance of excessive alcohol consumption, 
optimization of psychological wellbeing, provision of modern contraceptive/s $[1,8]$. Information on these ten contents of PCC was derived from the response to the question "Prior to your last pregnancy, did you received any of the following services at least once? 'Have you got any vaccination?', 'Have you got any contraceptive?'... Answer categories were developed for each practice assessment question as' $\mathrm{YES}=1^{\prime}$ and' $\mathrm{No}=0$. It is possible for a single mother may get a vaccination or modern contraceptive several times prior to pregnancy. However, as the mother was asked to report any service at least once, the response for any action was recorded as a single action. On the basis of responses, we have created a composite index of PCC content as our outcome variable which comprises a simple count of the number of elements of care received. The variable had a minimum value of zero indicating that the women did not receive any PCC services and a maximum value of ten indicating that the women received services for all the ten elements.

\section{Explanatory variables}

Household wealth index: a composite measure of respondents' socio-economic status was computed using PCA based on data from sustainable household goods and equipment, livestock ownership, quintal crop production, the average projected monthly income, agricultural land in hectares, and residential housing characteristics. Finally, the first component which explained maximum factor scores were split into quintiles [14].

Women's Autonomy in household decision-making: A woman is said to be autonomous of decision-making power when she decides on at least one of the following three issues alone or jointly (with her husband): (1) the health of the woman (personal decision-making authority), (2) big transactions (economic decision-making authority), and (3) visits to friends or relatives (mobility decision-making authority)otherwise considered as nonautonomous when the husband alone or a third person decides on seeking MNCH services [14, 42, 43].

Knowledge on PCC:: If a woman correctly answered at least $50 \%$ of the correct answers to eight PCC knowledge assessment questions, she was classified as knowledgeable; otherwise, she was classified as not knowledgeable $[31,44]$.

Being a household model (MHH): a family that implements all health extension packages and has received certificates of appreciation from responsible bodies [45].

Perceived distance to the nearest health facility: This was determined by the respondents' answers to questions of how long they walked to the health facilities. If mothers reported walking for less than $30 \mathrm{~min}$ to reach the nearest health facility, this was coded as 'closer;' otherwise, it was coded as 'far' [46].

Preconception care unit: This is a unit or space where preconception care for women was offered before becoming pregnant [31].

\section{Results}

The study included a total of 591 mothers who gave birth within the last 12 months, which resulted in a $98.9 \%$ response rate.

\section{Socio-demographic characteristics of respondents}

The age of respondents ranges from 16 to 44 years with a mean age of 27.9 and with a standard deviation of \pm 5.4 years. The majority of respondents were married (86.3\%) and more than one-third $(36.2 \%)$ had attended primary education. The predominant ethnic group was Guraghe (87.4\%) and almost half (47.7\%) were Orthodox by religion (Table 1$)$.

\section{Obstetric characteristics of respondents}

The obstetric characteristic assessment found that nearly half $(49.6 \%)$ of participants were multiparous. 'Majority of the participants, 536 (85.8\%) visited health facilities for ANC service at least once for their recent pregnancy and one-third (33.2\%) of them got four or more visits. More than half $(328,55.5 \%)$ of respondents used modern family planning, and there were 138 (23.3\%) among those existing users. One hundred forty-nine (25.2\%) of study participants reported a prior history of adverse birth outcomes, in which 45 (30.2\%) and 33 (22.1\%) of women reported a history of spontaneous abortion and stillbirth, respectively (Table 2).

\section{Health system-related characteristics of the respondents}

Concerning the accessibility of health services, the majority $(79.7 \%)$ of mothers have access to health facilities within fewer than 30 min and more than half (56.5\%) use the foot as a means of transport. The availability of adequate medication and laboratory facilities nearby was recorded by almost three-fifths $(58.2 \%)$ and more than half $(53.6 \%)$ of the participants respectively. The availability of PCC guidelines was mentioned by nearly one-third of respondents, 193 (32.6\%). For decision-making autonomy, the majority of participants $(84.4 \%)$ were autonomous (Table 3).

\section{Respondents' level of knowledge of PCC}

The level of women's knowledge about preconception care was determined by their correct responses to eight knowledge assessment questions, and 269 (45.5\%) of those who responded were knowledgeable. Almost seven out of ten $(69.4 \%)$ of women heard about PCC. More 
Table 1 Distribution of Socio-demographic characteristics of study participants in Wolkite town, Southern Ethiopia, February $1-15,2020$

\begin{tabular}{|c|c|c|}
\hline Variables categories & Frequency & Percent \\
\hline \multicolumn{3}{|l|}{ Age $(n=591)$} \\
\hline$\leq 24$ & 218 & 36.9 \\
\hline $25-34$ & 289 & 48.9 \\
\hline $35+$ & 84 & 14.2 \\
\hline \multicolumn{3}{|l|}{ Marital status $(n=591)$} \\
\hline Married & 510 & 86.3 \\
\hline Divorced & 40 & 6.8 \\
\hline Widowed & 24 & 4.1 \\
\hline Single/never married & 17 & 2.8 \\
\hline \multicolumn{3}{|l|}{ Ethnicity $(n=591)$} \\
\hline Guraghe & 510 & 86.3 \\
\hline Amhara & 66 & 11.2 \\
\hline Others* & 15 & 2.5 \\
\hline \multicolumn{3}{|l|}{ Religion $(n=591)$} \\
\hline Orthodox & 282 & 47.7 \\
\hline Muslim & 239 & 40.4 \\
\hline Protestant & 64 & 10.8 \\
\hline Catholic & 6 & 1.1 \\
\hline \multicolumn{3}{|c|}{ Mother's education level $(n=591)$} \\
\hline No formal education & 112 & 19.0 \\
\hline Primary education & 214 & 36.2 \\
\hline Secondary education & 182 & 30.8 \\
\hline College and above & 83 & 14.0 \\
\hline \multicolumn{3}{|c|}{ Mother's occupation ( $n=591)$} \\
\hline Housewife & 235 & 39.8 \\
\hline Private business work & 183 & 31.0 \\
\hline Government employer & 130 & 22.0 \\
\hline Student & 43 & 7.2 \\
\hline \multicolumn{3}{|c|}{ Husband's education level $(n=510)$} \\
\hline No formal education & 102 & 20.1 \\
\hline Primary education & 151 & 29.6 \\
\hline Secondary education & 167 & 32.7 \\
\hline College and above & 90 & 17.6 \\
\hline \multicolumn{3}{|c|}{ Husband occupation $(n=510)$} \\
\hline Merchant & 249 & 48.8 \\
\hline Farmer & 114 & 22.4 \\
\hline Government employer & 103 & 20.2 \\
\hline Daily laborer & 44 & 8.6 \\
\hline \multicolumn{3}{|l|}{ Family size $(n=591)$} \\
\hline$>5$ & 145 & 24.5 \\
\hline$\leq 5$ & 446 & 75.5 \\
\hline \multicolumn{3}{|c|}{ Household wealth status $(n=591)$} \\
\hline Poorest & 106 & 17.9 \\
\hline Poorer & 112 & 19.0 \\
\hline Middle & 131 & 22.1 \\
\hline Rich & 125 & 21.2 \\
\hline Richest & 117 & 19.8 \\
\hline
\end{tabular}

*Other ethnicity $=$ Oromo, Tigri than half of the participants (55.7\%) knew at least one behavioral risk factor for a childbearing woman, such as alcohol consumption, cigarette smoking, and illegal drug intake, which could be prevented by having PCC. Nearly half (49.9\%) of mothers were aware of the health benefits of receiving PCC. At least one primary message that could be transmitted during PCC was known by 236(39.9\%) of respondents (Table4).

\section{The practice of preconception care (PCC)}

The current study centered on the ten core elements of PCC services, as previously stated. The mean $( \pm S D)$ score of PCC item uptake was $3.92( \pm 1.98)$ with minimum and maximum scores of 1 and 10 respectively. Only 6.4\% (95\% CI 4.2, 8.1) of mothers received all ten selected items of PCC services. Regarding the individual components of care, the most common item received by $67.2 \%$ of mothers was folate supplementation, closely followed by vaccination by $61.9 \%$ of mothers. The least received element was services focused on improving psychological wellbeing for the coming pregnancy and childbirth (16.1\%) (Fig. 1). In terms of service delivery points, more than half of the respondents (51.6\%) received such services at a health center, followed by $41.3 \%$ at a health post, and $7.1 \%$ at a hospital.

\section{Women's experience on PCC}

Of the total respondents, 397 (67.2\%) had prior experience of PCC with at least one item of care, while 194 (32.8\%) had no prior experience. Of those experienced respondents, $96(24.1 \%)$ reported that they had faced challenges during receiving care. Consumption of extended time during care provision, 43 (44.8\%) and long waiting time to get the health care providers, 31 (32.3\%) were the major challenges reported by the respondents (Fig. 2). Nearly a fifth, 116 (19.6\%) of respondents, had social influence while seeking care, with 69 (59.4\%) being influenced by their husband, $44(37.9 \%)$ by close friends and $16(13.8 \%)$ by their families. Just 91 (15.4\%) of the study participants did not obtain support from their husbands for PCC, with 56 (61.5\%) of the husbands lack awareness about how preconception care benefits couples, $29(31.8 \%)$ mentioning the time spent for care as wastage, and $21(23.1 \%)$ stating a fear of negative attitudes in the future.

\section{Determinants of the practice of preconception care (PCC)} Results of the multivariable generalized linear regression analysis with a Poisson link identified, Six variables, namely; mother education status, perceived time spent to reach nearby health facilities, availability of PCC unit, mother's knowledge on PCC, being a model household, and having maternal health service autonomy were 
Table 2 Obstetric characteristics of respondents who gave birth within the last 12 months in Wolkite town, Southern Ethiopia, February 1-30, 2020

\begin{tabular}{|c|c|c|}
\hline Variable categories & Frequency(n) & Percentage \\
\hline \multicolumn{3}{|l|}{ Parity $(N=591)$} \\
\hline Primipara & 122 & 20.6 \\
\hline Multipara & 293 & 49.6 \\
\hline Grand multipara & 176 & 29.8 \\
\hline \multicolumn{3}{|c|}{ Modern FP utilization $(\mathrm{N}=591)$} \\
\hline Yes & 328 & 55.5 \\
\hline No & 263 & 45.5 \\
\hline \multicolumn{3}{|l|}{ FP by method mix $(n=591)$} \\
\hline Oral contraceptives & 108 & 32.9 \\
\hline Injectable & 130 & 39.6 \\
\hline Implants & 55 & 16.8 \\
\hline IUD & 35 & 10.7 \\
\hline \multicolumn{3}{|l|}{ ANC attendance } \\
\hline Yes & 528 & 89.3 \\
\hline No & 63 & 10.7 \\
\hline \multicolumn{3}{|c|}{ Frequency of ANC visit $(n=528)$} \\
\hline One visit & 59 & 11.2 \\
\hline Two visits & 91 & 17.2 \\
\hline Three visits & 185 & 35.1 \\
\hline Four and more visits & 193 & 36.5 \\
\hline \multicolumn{3}{|c|}{ Place of delivery service $(\mathrm{N}=591)$} \\
\hline Health center & 445 & 75.3 \\
\hline Hospital & 110 & 18.6 \\
\hline Health post & 24 & 4.1 \\
\hline Home & 12 & 2.0 \\
\hline \multicolumn{3}{|c|}{ Having a History of adverse birth outcome $(N=591)$} \\
\hline Yes & 149 & 25.2 \\
\hline No & 442 & 74.8 \\
\hline \multicolumn{3}{|c|}{ Types of adverse birth outcome $(N=149)$} \\
\hline Spontaneous abortion & 45 & 30.2 \\
\hline Preterm birth & 32 & 21.5 \\
\hline Stillbirth & 33 & 22.1 \\
\hline Neonatal death & 25 & 16.8 \\
\hline Congenital anomalies & 14 & 9.4 \\
\hline \multicolumn{3}{|c|}{ History of unintended pregnancy $(\mathrm{N}=591)$} \\
\hline Yes & 98 & 16.6 \\
\hline No & 493 & 83.4 \\
\hline
\end{tabular}

defined as determinants of the practice of PCC (Table5). The level of education attained by the mother was found to have a significant positive relationship with the receipt of PCC services. Mothers with no formal education were $16 \%$ less likely to practice PCC than mothers with a college education or above [AOR 0.84, CI 0.73, 0.97]. Perceived time spent to reach nearby health facilities found as a PCC determinant. Mothers who had to travel more than 30 min to get to a health facility were $31 \%$ less likely to use PCC [AOR 0.69, CI 0.58, 0.83]. Women's autonomy was significantly associated with their use of the PCC services. Non-autonomous women were 15\% less likely than autonomous women to receive PCC services [AOR 0.85, CI 0.75, 0.96]. Furthermore, the availability of a PCC unit was found to be a significant predictor of PCC utilization. The existence of a PCC unit nearby was found to increase the likelihood of PCC service uptake by 46\% [AOR 1.46; 95\%CI 1.17, 1.57]. Maternal knowledge 
Table 3 Health services related characteristics of respondents in Wolkite town, Southern Ethiopia, 1-30 February 202

\begin{tabular}{|c|c|c|}
\hline Variables categories & Frequency & Percent \\
\hline \multicolumn{3}{|c|}{ Availability of adequate laboratory service $(n=591)$} \\
\hline Yes & 317 & 53.6 \\
\hline No & 239 & 40.4 \\
\hline I don't know & 35 & 5.9 \\
\hline \multicolumn{3}{|c|}{ Availability of adequate medication $(n=591)$} \\
\hline Yes & 344 & 58.2 \\
\hline No & 219 & 37.1 \\
\hline I don't know & 28 & 4.7 \\
\hline \multicolumn{3}{|c|}{ Availability of PCC unit $(\mathrm{n}=591)$} \\
\hline Yes & 239 & 40.4 \\
\hline No & 321 & 54.3 \\
\hline I don't know & 31 & 5.2 \\
\hline \multicolumn{3}{|c|}{ Availability of Guideline $(n=591)$} \\
\hline Yes & 193 & 32.6 \\
\hline No & 398 & 62.4 \\
\hline \multicolumn{3}{|c|}{ Perceived distance to reach nearby health facility on foot $(n=591)$} \\
\hline$\leq 1 \mathrm{~h}$ & 471 & 79.7 \\
\hline$>1 \mathrm{~h}$ & 120 & 20.3 \\
\hline \multicolumn{3}{|c|}{ Means of transportation $(n=591)$} \\
\hline On foot & 334 & 56.5 \\
\hline By Bajaj/Taxi & 210 & 35.5 \\
\hline By Private vehicle & 47 & 8.0 \\
\hline \multicolumn{3}{|c|}{ Autonomy to maternal health service $(n=591)$} \\
\hline By joint decision & 216 & 36.5 \\
\hline By self-decision & 283 & 47.9 \\
\hline By husband decision & 92 & 15.6 \\
\hline \multicolumn{3}{|c|}{ From whom you receive health care access assistance $(n=591)$} \\
\hline From my husband & 431 & 72.9 \\
\hline From relatives & 111 & 18.8 \\
\hline From families & 31 & 5.2 \\
\hline From neighbors & 18 & 3.0 \\
\hline \multicolumn{3}{|c|}{ Being a model household $(n=591)$} \\
\hline Yes & 322 & 54.5 \\
\hline No & 269 & 45.5 \\
\hline
\end{tabular}

of PCC was also an important predictor of the receipt of PCC items. Respondents with good knowledge of PCC have had a $34 \%$ higher chance of utilizing recommended items of PCC service [AOR 1.34, CI 1.13, 1.65]. Compared to respondents who were not from model households (MHHs), those respondents from $\mathrm{MHHs}$ had a $31 \%$ higher likelihood of receiving PCC services items [AOR $1.31,95 \%$ CI 1.12, 1.45] (Table 5).

\section{Discussion}

The current study found that only $38(6.4 \%)$ of respondents received all the ten WHO recommended items of preconception care services before they underwent their last pregnancy. The mean $( \pm \mathrm{SD})$ score for receiving PCC service items was $3.99( \pm 1.99)$. This suggests that most of the study participants did not adopt the PCC elements suggested by WHO and CDC [1, $7,47]$. The justification for this may be that PCC service provision was given less attention, and the majority of the current focus areas were prenatal care and skilled delivery services. Furthermore, a substantial number of mothers were unaware of PCC programs, which might lead to low uptake. Therefore, town health departments and health care providers must work together to integrate the $\mathrm{PCC}$ with routine maternal and child health programs, as well as strengthen 
Table 4 Knowledge of respondents on PCC in Wolkite town, Southern Ethiopia, February 1-30, 2020

\begin{tabular}{|c|c|c|}
\hline Knowledge assessment variables & Frequency & Percent \\
\hline \multicolumn{3}{|l|}{ Source of information about the PCC $(n=591)$} \\
\hline Health professionals at the health center and Hospitals & 248 & 41.9 \\
\hline Health extension workers & 288 & 48.7 \\
\hline Friends & 169 & 28.6 \\
\hline Mass media & 142 & 24.0 \\
\hline No, I didn't hear about PCC & 181 & 30.6 \\
\hline \multicolumn{3}{|l|}{ Do you know the direct beneficiaries of PCC? $(n=591)$} \\
\hline Only women & 198 & 33.5 \\
\hline Only men & 75 & 12.7 \\
\hline Both men and women & 318 & 53.8 \\
\hline \multicolumn{3}{|l|}{ Do you know a place where a woman can get a PCC? $(n=591)$} \\
\hline At home level & 49 & 8.3 \\
\hline At health institution & 114 & 19.3 \\
\hline At home and health institution & 182 & 30.7 \\
\hline I don't know & 246 & 41.6 \\
\hline \multicolumn{3}{|c|}{ Can you list at least one pregnancy disorder or health issue that can happen but can be minimized by PCC? $(n=591)$} \\
\hline Heart diseases including hypertension & 99 & 16.7 \\
\hline Diabetes mellitus & 107 & 18.1 \\
\hline STI/HIV & 118 & 19.9 \\
\hline Stress & 32 & 5.4 \\
\hline I don't know & 286 & 48.4 \\
\hline \multicolumn{3}{|c|}{ Can you discuss at least one behavioral risk factor for a childbearing woman that can be avoided by obtaining PCC? } \\
\hline Alcohol consumption & 257 & 43.4 \\
\hline Cigarette smoking & 236 & 39.9 \\
\hline Illegal drug intake & 68 & 11.5 \\
\hline I don't know & 258 & 43.6 \\
\hline \multicolumn{3}{|c|}{ Do you know of at least one intervention or message that can be given during the PCC to a woman? $(n=591)$} \\
\hline Folic acid supplementation & 166 & 28.1 \\
\hline Avoiding excess alcohol consumption & 86 & 14.5 \\
\hline Adequate meal frequency & 99 & 16.7 \\
\hline Cessation of cigarette smoking & 112 & 18.9 \\
\hline Free from stress & 66 & 11.1 \\
\hline I don't know & 355 & 60.1 \\
\hline \multicolumn{3}{|l|}{ Do you know about PCC service providers? $(n=591)$} \\
\hline Health care workers at hospitals and health center & 293 & 49.6 \\
\hline Health extension workers & 104 & 17.6 \\
\hline I don't know & 235 & 39.7 \\
\hline
\end{tabular}

awareness-raising efforts to encourage better use of PCC service components.

The most common item received in the study area was micronutrient supplementation (67.2\%), which is lower than a report from a similar study conducted in Mekele city, northern Ethiopia (86.3\%) [30], but higher than another study conducted in western Ethiopia (7.7\%) [32]. The disparity may be due to differences in the study area in which the subsequent study with low prevalence [32] was conducted among rural women.
Vaccination was the other item received by the majority of respondents $(61.9 \%)$ and is comparable to a similar study conducted in Mekelle City, Northern Ethiopia $(60.8 \%)$ [30], and higher than another study conducted in Western Ethiopia (17.6\%) [32]. In the current study area, the adoption of all remaining items of PCC service also requires due emphasis, particularly on the pre-pregnancy contraceptive provision (39.2\%), STI screening and management (37.1\%), and psychological health optimization (16.1\%). 
Uptake of Contents of PCC

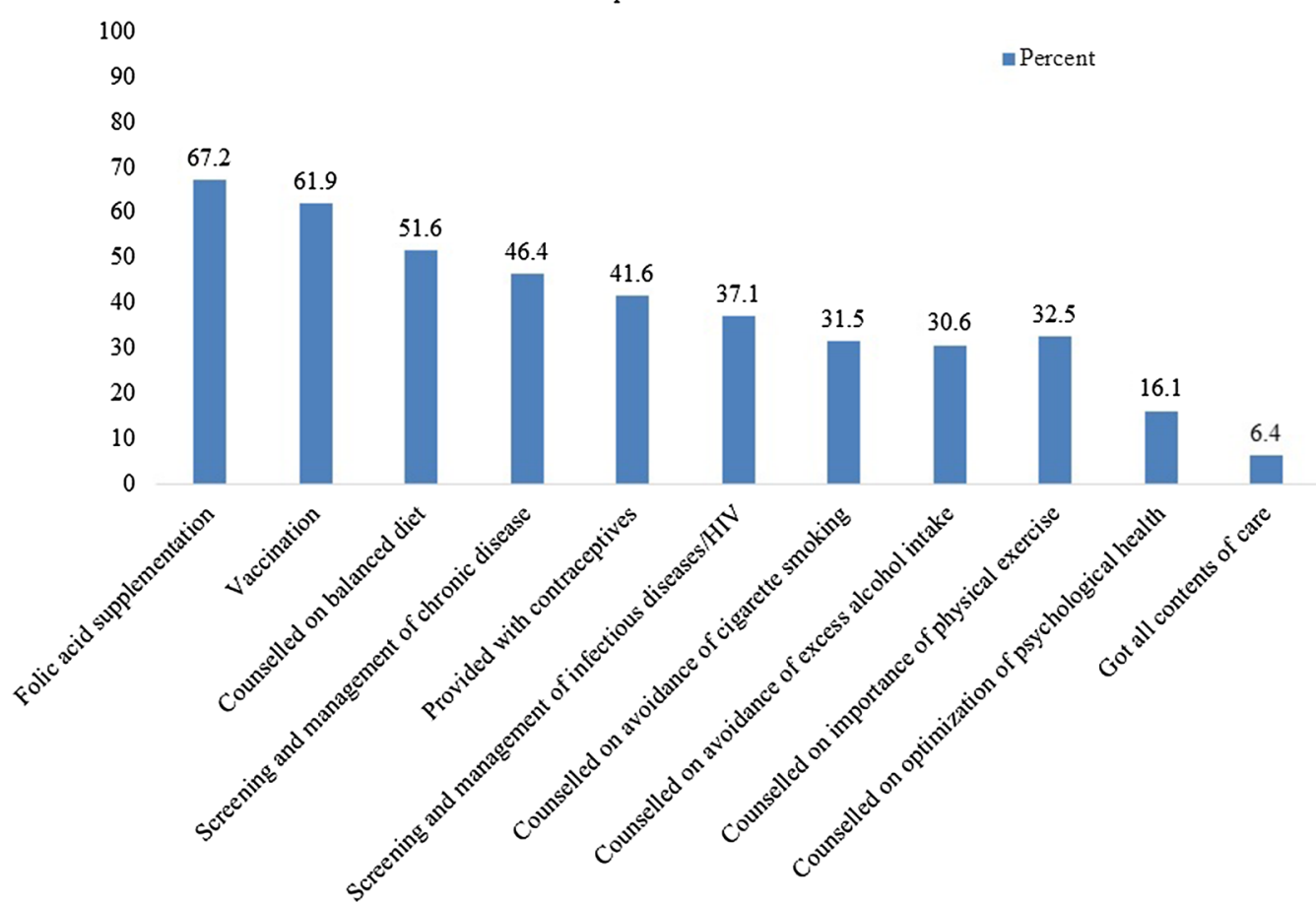

Fig. 1 The proportion of women receiving preconception care packages recommended by the World Health Organization in Wolkite town, Southern Ethiopia, $2020(N=591)$

Maternal education, the availability of the PCC unit, maternal knowledge of the PCC, being a model household $(\mathrm{MHH})$, and having maternal health service autonomy were identified as significant determinants of PCC practices.

The mother's educational level was found to have a significant association with the receipt of PCC service items. Similar findings were observed in studies conducted in China, Sri Lanka, Saudi Arabia, and Northern Ethiopia [27-29, 33]. The possible justification could be

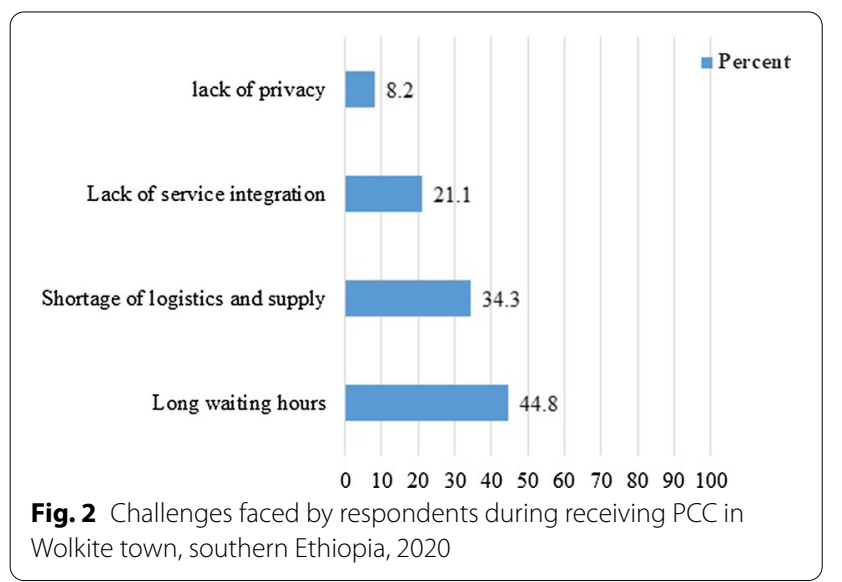

that women with a higher level of education have more access to information about PCC with strong information-processing skills, leading to the uptake of those recommended contents of care. It is also recognized that education also increases the health-seeking behaviors of mothers by increasing their autonomy and creating greater confidence and ability to make decisions about their health $[36,48]$.

Also, the current study revealed a significant positive association between maternal knowledge of PCC and the use of PCC service items. Compared to those mothers who were not knowledgeable, the chances of PCC practice were 1.34 times greater for knowledgeable mothers. This result is in line with the studies conducted in China, Saudi Arabia, and northern Ethiopia [29, 31, 49]. This is plausible because the more PCC knowledge a mother has, such as the advantages, content, place, and duration of the visit, the more likely she is to adopt the suggested PCC content. As a result, a concerted effort is needed from the responsible bodies in the town to improve women's knowledge on PCC through behavioral change communication.

The distance (perceived time spent to reach health facilities) was identified as significant predictors of PCC uptake. Mothers who travelled more than $30 \mathrm{~min}$ to access health facility were $31 \%$ less likely to practice PCC 
Table 5 Determinants of the practice of PCC among women of the reproductive age group using a multivariable generalized linear regression model with Poisson link in Wolkite Town, Southern Ethiopia, February 1-30, 2020

\begin{tabular}{|c|c|c|c|c|}
\hline Variables categories & $\begin{array}{l}\text { Mean of a component } \\
\text { of PCC }\end{array}$ & p-value & $\mathrm{AOR}(95 \% \mathrm{Cl})$ & p-value* \\
\hline \multicolumn{5}{|l|}{ Women's age $(N=591)$} \\
\hline $35+$ & 3.5 & $0.000^{\mathrm{a}}$ & $0.91(0.79,1.04)$ & 0.288 \\
\hline $25-34$ & 3.8 & & $0.96(0.87,1.05)$ & 0.394 \\
\hline$\leq 24$ & 4.2 & & 1 & \\
\hline \multicolumn{5}{|l|}{ Women's education level $(n=591)$} \\
\hline No formal education & 3.5 & $0.000^{\mathrm{a}}$ & $0.74(0.63,0.97)$ & 0.009 \\
\hline Primary education & 3.7 & & $0.88(0.77,0.99)$ & 0.231 \\
\hline Secondary education & 4.1 & & $0.89(0.78,1.11)$ & 0.413 \\
\hline College and above & 4.6 & & 1 & \\
\hline \multicolumn{5}{|l|}{ Wealth index $(n=591)$} \\
\hline Richest & 4.1 & $0.135^{\mathrm{a}}$ & $1.026(0.89,1.17)$ & 0.549 \\
\hline Rich & 4.2 & & $1.06(0.93,1.21)$ & 0.631 \\
\hline Middle & 3.9 & & $1.01(0.89,1.150$ & 0.549 \\
\hline Poorer & 3.8 & & $0.95(0.83,1.083)$ & 0.569 \\
\hline Poorest & 3.6 & & 1 & \\
\hline \multicolumn{5}{|l|}{ Family size $(n=591)$} \\
\hline$<5$ & 4.0 & $0.115^{b}$ & & \\
\hline$\geq 5$ & 3.7 & & & \\
\hline \multicolumn{5}{|l|}{ Parity $(n=591)$} \\
\hline Grand multiparous & 3.7 & $0.000^{\mathrm{a}}$ & $0.95(0.84,1.08)$ & 0.608 \\
\hline Multiparous & 3.8 & & $0.92(0.83,1.03)$ & 0.402 \\
\hline Primiparous & 4.5 & & 1 & 1 \\
\hline \multicolumn{5}{|c|}{ Pre-pregnancy utilization of Contraceptives $(n=591)$} \\
\hline No & 3.6 & $0.238^{b}$ & & \\
\hline Yes & 4.1 & & & \\
\hline \multicolumn{5}{|c|}{ History of adverse birth outcome $(n=591)$} \\
\hline No & 3.6 & $0.001^{b}$ & $0.99(0.90,1.09)$ & \\
\hline Yes & 4.3 & & 1 & \\
\hline \multicolumn{5}{|l|}{ Availability of PCC unit $(n=591)$} \\
\hline Yes & 4.4 & $0.000^{b}$ & $1.46(1.17,1.57)$ & $<0.001$ \\
\hline No & 3.5 & & 1 & \\
\hline \multicolumn{5}{|c|}{ Perceived time to reach Health facility $(n=591)$} \\
\hline $\operatorname{Far}(>30 \mathrm{~min})$ & 3.2 & $0.000^{b}$ & $0.69(0.58,0.83)$ & $<0.001$ \\
\hline Close $(<=30 \mathrm{~min})$ & 4.1 & & 1 & \\
\hline \multicolumn{5}{|c|}{ Autonomy in decision making $(n=591)$} \\
\hline By husband and other parties & 3.4 & $0.000^{\mathrm{a}}$ & $0.85(0.75,0.96)$ & 0.025 \\
\hline By joint decision & 3.7 & & $0.94(0.85,1.03)$ & 0.281 \\
\hline By her decision & 4.3 & & 1 & \\
\hline \multicolumn{5}{|l|}{ Knowledge of PCC $(n=591)$} \\
\hline Not knowledgeable & 3.3 & $0.000^{b}$ & 1 & \\
\hline Knowledgeable & 4.6 & & $1.34(1.16,1.62)$ & $<0.001$ \\
\hline \multicolumn{5}{|l|}{ Being MHH $(n=591)$} \\
\hline No & 3.3 & $0.000^{b}$ & 1 & \\
\hline Yes & 4.5 & & $1.31(1.18,1.52)$ & $<0.001$ \\
\hline
\end{tabular}

Key: 1: reference category

AOR adjusted odds ratio

$p$-value*: indicates $p$-value at Generalized linear model with Poisson log link $p$-values with ${ }^{\mathrm{a}}$ indicates descriptive analysis by using ONE WAY ANOVA $\mathrm{p}$-value with ${ }^{\mathrm{b}}$ indicates independent $\mathrm{t}$-test analysis 
than their counterparts. While universal access to the $\mathrm{MNCH}$ continuum of care is strongly advocated, there is still a huge difference in the ease of access to health services $[50,51]$. This means that to access those mothers who are far from the nearest health facilities, outreach programs should be improved.

The availability of PCC units in a nearby health facility was also correlated with increased odds of using PCCs. Women who mentioned that a preconception care unit is available had a $46 \%$ higher chance of using PCC than women who did not know about the existence of a preconception care unit, and this finding is confirmed by a study conducted in Debire Birhan town, northern Ethiopia [30]. This may be that if health facilities had a functioning PCC unit, mothers would have the opportunity to be informed about the importance of getting PCC during their visit, which would enhance PCC uptake. Therefore, a concerted effort from all stakeholders is expected to improve and integrate $\mathrm{PCC}$ into the existing $\mathrm{MNCH}$ service delivery points.

The autonomy of women in decision-making about their household activities is significantly associated with the practice of PCC in this report. For mothers whose autonomy is at the hands of their husbands or other groups, the likelihood of obtaining a PCC was lower compared to an autonomous one. This research is supported by by studies elsewhere that indicate uptake of maternal health care services is affected by women's positions in decision making $[42,52,53]$. A potential argument may be that there is a greater chance for autonomous women to access reproductive health care services [54]. Also, the control of women over household resources could have a significant positive impact on both the demand for and the uptake of MNCH services [48].

Among mothers who were from model households $(\mathrm{MHH})$, the probability of PCC practice was greater. Those mothers from MHHs were 1.3 times more likely than their counterparts to practice PCC. This could be because, Health Extension Workers (HEWs) spend more time on the capacity building portion for model HHs through intensive training, support, and follow-up and family education on MNCH services for those selected to be role models $[55,56]$. In contrast to their counterparts, this successive preparation, support, and follow-up could bring skill development and make them exercise PCC adequately and effectively.

There were both strengths and shortcomings in this research. The study is the first of its kind to assess the determinants of the practice of PCC in this study area. The results of the study may have significant policy implications for the further enhancement of PCC services. Although the necessary efforts have been made to mitigate the potential shortcomings of this study, readers should be careful when interpreting the results. Since the study was based on self-reports, the respondents might be prone to social desirability bias. Finally, because women were asking about incidents that had already occurred during the last one year before this study, there may be a risk of recall bias.

\section{Conclusion}

In the study area, the mean score and overall PCC practice were low. Determinants for PCC practice were recognized for the level of education of mothers, mother's knowledge of $\mathrm{PCC}$, time spent reaching nearby health facilities, availability of PCC units, being a model household, and women's autonomy in decision-making. Therefore, increased efforts are needed by policymakers to improve the autonomy of women in decision-making. By integrating with routine $\mathrm{MNCH}$ service delivery points, the Health Unit of the city should focus on the functionality of PCC units. Besides, to increase maternal knowledge on PCC, health workers must give due focus on improving behavioral change communication operations.

\section{Abbreviations \\ AOR: Adjusted odds ratio; CDC: Center for Disease Control; COC: Continuum of Care; PCA: Principal Component Analysis; PCC: Preconception Care; SDG: Sustainable Development Goal; SPSS: Statistical product and service solutions; WHO: World Health Organization. \\ Acknowledgements \\ We are very grateful to the health unit of Wolkite town and Wolkite University for all the support we have been given to conduct this report. We are grateful to our data collectors, supervisors, and the study participants for their efforts throughout the study.}

\section{Authors' contributions}

$\mathrm{AH}$ : wrote the proposal, supervised the collection of data, the entry, and analysis of data, and finally engaged in the writing and examination of the manuscript. SD: Participated in the design, methodology, data analysis, and reviewing of the manuscript critically. DH: Participated in the data review and during the study provided critical and progressive suggestions. All authors read and approved the final manuscript.

Funding

None.

Availability of data and materials

All data are fully available without restriction.

\section{Declarations}

Ethics approval and consent to participate

Ethical clearance was obtained from the Ethical Review Board of Wolkite University, department of public health. Also, an official letter of cooperation was granted by the Guraghe zone health department and Wolkite town health unit. For those aged 18 and over, written informed consent was obtained from study participants. Besides, after explaining the study goals and procedures, consent was taken from a parent or guardian using normal disclosure processes for those participants less than 18 years of age. A specific ID number was allocated to preserve the anonymity of the questionnaire. The privacy and confidentiality of participants were guaranteed before data collection. The confidentiality of the information was ensured and the respondent's privacy 
was respected. Participants were also well aware that the data they generated during the analysis would only be used for the research purpose and would not be revealed to anyone outside the research team.

\section{Consent for publication}

Not applicable.

\section{Competing interests}

We would like to assure you that, with full responsibility and communication, the document has been submitted. We indicated that there is no conflict of interest with other individuals or organizations that could influence or bias the content of the paper inappropriately.

\section{Author details}

${ }^{1}$ Department of Public Health, College of Medicine and Health Sciences, Wachemo University, Hosanna, Ethiopia. ${ }^{2}$ Department of Public Health, College of Medicine and Health Sciences, Wolkite University, Wolkite, Ethiopia. ${ }^{3}$ Department of Reproductive Health and Nutrition, School of Public Health, College of Medicine and Health Sciences, Wolaita Soddo University, Soddo, Ethiopia.

Received: 4 November 2020 Accepted: 11 May 2021

Published online: 21 May 2021

\section{References}

1. Organization WH. Meeting to develop a global consensus on preconception care to reduce maternal and childhood mortality and morbidity: World Health Organization Headquarters, Geneva, 6-7 February 2012 meeting report. 2013.

2. Mason E. Preconception care; advancing from important to do and can be done to is being done and is making a difference, in low income countries. Reprod Health. 2014. https://doi.org/10.1186/ 1742-4755-11-S3-S8.

3. Johnson K, Posner SF, Biermann J, Cordero JF, Atrash HK, Parker CS, Boulet S, Curtis MG. Recommendations to improve preconception health and Health Care-United States: report of the CDC/ATSDR preconception care work group and the select panel on preconception care. Morb Mortal Wkly Rep Recomm Rep 2006;55(6):1-CE.

4. Van Der Zee B, et al. Preconception care: an essential preventive strategy to improve children's and women's health. J Public Health Policy. 2011;32(3):367-79.

5. Finer LB, Zolna MR. Unintended pregnancy in the United States: incidence and disparities, 2006. Contraception. 2011;84(5):478-85.

6. Dean $\mathrm{S}$, et al. Setting research priorities for preconception care in low-and middle-income countries: aiming to reduce maternal and child mortality and morbidity. PLoS Med. 2013;10(9):e1001508.

7. Centers for Disease Control and Prevention. Maternal health: advancing the health of mothers in the 21st century. 2016.

8. Temel S. The Dutch national summit on preconception care: a summary of definitions, evidence and recommendations. DJ Community Genet. 2015;6:107-15.

9. DeWeger FJ. Advanced maternal age, short inter-pregnancy interval, and perinatal outcome. Am J Obstet Gynecol. 2011;204(5):421-e1.

10. Mohan S, et al. Analysis of risk factors, maternal and fetal outcome of spontaneous preterm premature rupture of membranes: a cross sectional study. Int J Reprod Contracept Obstet Gynecol. 2017;6(9):3781-7.

11. Jack BW, et al. The clinical content of preconception care: an overview and preparation of this supplement. Am J Obstet Gynecol. 2008;199(6):S266-79.

12. Alkema $L$, et al. Global, regional, and national levels and trends in maternal mortality between 1990 and 2015, with scenario-based projections to 2030: a systematic analysis by the UN Maternal Mortality Estimation Inter-Agency Group. Lancet. 2016;387:462-74.

13. Bhutta ZA, Chopra M, Axelson H, Berman P, Boerma T, Bryce J, Bustreo F, Cavagnero E, Cometto G, Daelmans B. Taking stock of maternal, newborn, and child survival. Countdown to decade report(2000-10). Lancet. 2012;375(9730):2032-44.
14. Central Statistical Agency (CSA) [Ethiopia], ICF. Ethiopia Demographic and Health Survey 2016. Addis Ababa, Ethiopia, and Rockville, Maryland: CSA and ICF; 2016.

15. Say, L., et al., Global Causes of Maternal Death: A WHO Systematic Analysis. Lancet Global Health, 2014. 2.

16. Maxwell G. Preterm premature rupture of membranes. Obstet Gynecol Surv. 1993;48:e323-33.

17. Merenstein GWL. Premature rupture of the membranes: neonatal consequences. Semin Perinatol. 1996;20:375-80.

18. Moos MK, et al. Healthier women, healthier reproductive outcomes: recommendations for the routine care of all women of reproductive age. Am J Obstet Gynecol. 2008;199:e280-9.

19. Williams L, Zapata LB, D’Angelo DV. Associations between preconception counseling and maternal behaviors before and during pregnancy. Matern Child Health J. 2012. https://doi.org/10.1007/s10995-011-0932-4.

20. Kaya D. Risk factors of preterm premature rupture of membranes at Mulago hospital Kampala. East Afr Med J. 2001. https://doi.org/10.4314/ eamj.v78i2.9090.

21. Jack BW, Culpepper L. Preconception care: risk reduction and health promotion in preparation for pregnancy. JAMA. 1990;264(9):1147-9.

22. Kay J, et al. Recommendations to improve preconception health and healthcare-United States. A report of the CDC/ATSDR Preconception Care Work Group and the Select Panel on Preconception Care. Atlanta: 2006/55(RR06):1-23.

23. Cotton $\mathrm{DHL}$, et al. Use of amniocentesis in preterm gestation with ruptured membranes. Obstet Gynecol. 1984;63:38-43.

24. Estimates by WHO, UNICEF, UNFPA, World Bank Group and the United Nations population division. 2015, Geneva: World Health Organization.

25. Ferguson SESG, et al. Preterm premature rupture of membranes: nutritional and socioeconomic factors. Obstet Gynecol. 2002. https://doi.org/ 10.1016/S0029-7844(02)02380-3.

26. Choudhary MRS, Chowdhary J, Garg S. Pre and post conception risk factors in PROM. Int J Res Med Sci. 2017;3:2594-8.

27. Yan D, et al. Survey on the implementation of preconception Care in Shanghai, China. Paediatr Perinat Epidemiol. 2015;29:492-500.

28. Patabendige M, Goonewardene I. Preconception care received by women attending antenatal clinics at a Teaching Hospital in Southern Sri Lanka. Sri Lanka J Obstet Gynaecol. 2013;35:3.

29. Madanat AY, Sheshah EA. Preconception care in Saudi women with diabetes mellitus. J Fam Community Med. 2016;23:109.

30. Asresu TT, et al. Mothers' utilization and associated factors in preconception care in northern Ethiopia: a community based cross sectional study. BMC Pregnancy Childbirth. 2019;19(1):347.

31. Demisse $T L$, et al. Utilization of preconception care and associated factors among reproductive age group women in DebreBirhan town, north Shewa, Ethiopia. Reprod Health. 2019. https://doi.org/10.1186/ s12978-019-0758-x.

32. Fekene DB, et al. Knowledge, uptake of preconception care and associated factors among reproductive age group women in West Shewa zone, Ethiopia, 2018. BMC Womens Health. 2020;20(1):1-8.

33. Goshu Y, Liyeh T, Simegn Ayele A. Preconception care utilization and its associated factors among pregnant women in Adet, North-Western Ethiopia (Implication of Reproductive Health). J Women's Health Care. 2018;7(445):2167-0420.1000445.

34. Vishwakarma K, et al. Impact of premature rupture of membranes on maternal \& neonatal health in Central India. J Evid Based Med Healthc. 2015;2(49):8505-8.

35. Young CT, Arquia ML, Ray JT. Preconception care in low- and middleincome countries: new opportunities and a new metric. PLoS Med. 2013;10:e1001507.

36. Brajesh. Effect of women's empowerment on reproductive and child health services among South Asian Women. Demography India. 2017;46(2):95-112.

37. Chandra I, Sun L. Third trimester preterm and term premature rupture of membranes: is there any difference in maternal characteristics and pregnancy outcomes? J Chin Med Assoc. 2017;80(10):657-61.

38. Moos MK. From concept to practice: reflections on the preconception health agenda. J Women's Health. 2010;19:561-7.

39. Biratu AK, Addressing the high adverse pregnancy outcomes through the incorporation of preconception care (PCC) in the health system of Ethiopia [PHD]. Pretoria: University of South Africa (UNISA), 2017. 
40. Winkelmann R, Zimmermann KF. Count data models for demographic data. Math Popul Stud. 1994;4(3):205-21.

41. Cameron AC, Trivedi PK. Regression analysis of count data, vol. 53. Cambridge: Cambridge University Press; 2013.

42. Tiruneh FN, Chuang K-Y, Chuang Y-C. Women's autonomy and maternal healthcare service utilization in Ethiopia. BMC Health Serv Res. 2017;17(1):718.

43. Yeji F, Shibanuma A, Oduro A, et al. Continuum of care in a maternal, newborn and child health program in Ghana: low completion rate and multiple obstacle factors. PLoS ONE. 2015;10:e0142849.

44. Yitayal A. Women's knowledge and associated factors in preconception care in adet, west gojjam, Northwest Ethiopia: a community based cross sectional study. Reprod Health. 2017. https://doi.org/10.1186/ s12978-017-0279-4.

45. Darega B, et al. Institutional delivery and postnatal care services utilizations in Abuna Gindeberet District, West Shewa, Oromiya Region, Central Ethiopia: a community-based cross sectional study. BMC Pregnancy Childbirth. 2016;16(1):149.

46. Ayalew TW, Nigatu AM. Focused antenatal care utilization and associated factors in Debre Tabor Town, northwest Ethiopia, 2017. BMC Res Notes. 2018;11(1):819.

47. World Health Organization: preconception health; maximizing the gains of maternal and child health. World Health Organization 2013. Accessed at www.who.int/maternal-child-adolescent//document/concensuspreconception-care/en

48. Jejeebhoy SJ. Women's education, autonomy, and reproductive behaviour: experience from developing countries. OUP Catalogue. 1995.

49. You X, Tan H, Hu S, Wu J, Jiang H, Peng A, Dai Y, Wang L, Guo S, Qian $X$. Effects of preconception counseling on maternal health care of migrant women in China: a community-based, cross-sectional survey.
BMC Pregnancy Childbirth. 2015;15:55. https://doi.org/10.1186/ s12884-015-0485-4.

50. UN-DESA. "Sustainable Development Goal 3: ensure healthy lives and promote well-being for all at all ages,", 2017. Sustainable Development Knowledge Platform. 17 May 2017.

51. Straneo M, Fogliati P, Pellis I, Goodman C, Riva DD, Kisika F, et al. On the way to universal coverage of maternal services in Iringa rural District in Tanzania. Who is yet to be reached? Afr Health Sci. 2016;16(2): 420-8.

52. Chima V. Women autonomy and maternal healthcare services utilization among young ever-married women in Nigeria. Int I Nurs Midwifery. 2018;10(6):62-73.

53. Woldemicael G. Do women with higher autonomy seek more maternal health care? Evidence from Eritrea and Ethiopia. Health Care Women Int. 2010;31(7):599-620

54. Dyson T, Mick M. On kinship structure, female autonomy, and demographic behavior in India. Popul Dev Rev. 1983;9(1):35-60.

55. Wang $\mathrm{H}$, et al. Ethiopia health extension program: an institutionalized community approach for universal health coverage. The World Bank. 2016.

56. Karim AM, et al. Effect of Ethiopia's health extension program on maternal and newborn health care practices in 101 rural districts: a dose-response study. PLoS ONE. 2013;8(6):e65160.

\section{Publisher's Note}

Springer Nature remains neutral with regard to jurisdictional claims in published maps and institutional affiliations.
Ready to submit your research? Choose BMC and benefit from:

- fast, convenient online submission

- thorough peer review by experienced researchers in your field

- rapid publication on acceptance

- support for research data, including large and complex data types

- gold Open Access which fosters wider collaboration and increased citations

- maximum visibility for your research: over $100 \mathrm{M}$ website views per year

At $\mathrm{BMC}$, research is always in progress.

Learn more biomedcentral.com/submissions 